\title{
アンモニア-過酸化水素溶液溶解/黒鉛炉原子吸光法に よるヒ化ガリウムウェハー表面の極微量ケイ素の定量
}

\author{
大澤 恭子*，高 竜磨*，小園 修治 ${ }^{\circledR *}$
}

Determination of ultratrace amounts of silicon on gallium arsenide wafers by dissolution of the surface with an ammonia-hydrogen peroxide mixed solution and a measurement by graphite furnace AAS.

$$
\text { Kyoko Ohsawa, Ryuma TaKashi, and Shuji Kozono* }
$$

* Analysis and Physical Properties Center, Central Research Laboratory, Showa Denko K. K., Ohnodai 1-1-1, Midori-ku Chiba 267)

(Received 19 May 1997, Accepted 7 July 1997)

A method for the determination of ultratrace $\mathrm{Si}$ on $\mathrm{GaAs}$ wafers has been investigated. A $\mathrm{NH}_{4} \mathrm{OH}$ and $\mathrm{H}_{2} \mathrm{O}_{2}$ mixed solution was suitable for the dissolution of GaAs wafers. In the pretreatment procedure, a $\mathrm{NH}_{4} \mathrm{OH}$ and $\mathrm{H}_{2} \mathrm{O}_{2}$ mixed solution and a polypropylene ring was sandwiched between two GaAs wafers, so that it could dissolve the surface by shaking with a small volume of solution inside the polypropylene ring. The presence of $\mathrm{Ga}$ and $\mathrm{As}$ in the solution deteriorated the reproducibility of the $\mathrm{Si}$ measurement by graphite furnace AAS. The use of a $\mathrm{NH}_{4} \mathrm{Cl}$ and $\mathrm{HBr}$ mixed solution as a matrix modifier recovered the reproducibility. The lower determination limit was $2 \mathrm{ng} \mathrm{ml}^{-1}$, estimated as the concentration corresponding to 10-times the standard deviation of a blank solution. This value corresponded to a surface concentration of $14 \times 10^{11}$ atoms cm${ }^{-2}$ for 2 -inch wafer, and $4 \times 10^{11}$ atoms $\mathrm{cm}^{-2}$ for 3 -inch wafer. According to the analytical results of various GaAs wafer samples, it was found that the concentration of $\mathrm{Si}$ on the surface of GaAs wafers was in the range of $10^{11}-10^{13}$ atoms $\mathrm{cm}^{-2}$.

Keywords : trace analysis of silicon; GaAs wafer; $\mathrm{NH}_{4} \mathrm{OH}-\mathrm{H}_{2} \mathrm{O}_{2}$ solution; graphite furnace AAS; $\mathrm{NH}_{4} \mathrm{Cl}-\mathrm{HBr}$ matrix modifier solution.

\section{1 緒言}

ヒ化ガリウム $(\mathrm{GaAs})$ ウェハーは半導体発振子や発 光ダイオード等の基板に用いられるが，これらが今後更 に高性能化するのに伴い, GaAs ウェハーの高純度化が 重要となっている. その中で, ウェハーの表面〜数十 $\mathrm{nm}$ 付近に存在する $\mathrm{Na}, \mathrm{Si}, \mathrm{K}, \mathrm{Gr}, \mathrm{Fe} ; \mathrm{Ni}, \mathrm{Cu}$ 等の

* 昭和電工 (株) 総合研究所: 267 千葉県千葉市緑区大野 台 1-1-1
不純物は，接電リーク，耐電圧不良等の原因となるた め, 不純物量を把握することが必要である. GaAs 結晶 中及び GaAs ウェハ一表面の不純物の定量は中村ら ${ }^{1)}$,

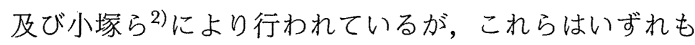
金属成分を対象としており，不純物として重要な元素の 一つである $\mathrm{Si}$ の定量は行われていなかった，又，二次 イオン質量分析法 (SIMS) による測定において得られ る值は相対值であるため, 不純物量を正確に把握するた めには湿式分析による定量が重要であると考えられる. 
今回, $\mathrm{GaAs}$ ウェハーの表面の $\mathrm{Si}$ 定量を目的とし， GaAs ウェハーを溶解し, 黒鉛炉原子吸光法 (GFAAS) により測定を行う方法について検討を行った. 溶解溶 液, 溶解方法, GFAAS 測定における共存 Ga 及び As の影響低減等について種々検討を行った結果, 面積濃度 換算で $10^{11} \sim 10^{12}$ atoms $\mathrm{cm}^{-2}$ の定量下限で定量するこ とができたので，以下に報告する.

\section{2 実験}

\section{$2 \cdot 1$ 装 置}

GFAAS は，パーキンエルマー製 Z-5100PG 型, HGA-600 型加熱炉, 及び AS-60 型オートサンプラーを 使用した．黒鉛炉は，同社製のパイロコーティング処理 を施した湾曲型プラットホーム付きのものを使用した.

ポリプロピレン製リングは内径 35 , 外径 39 , 厚さ 1 $\mathrm{mm}$ のもの (2 インチウェハー用), 及び内径 65 , 外径 69 , 厚さ $1 \mathrm{~mm}$ のもの (3 インチウェハー用) を使用し た.

\section{$2 \cdot 2$ 試 薬}

超純水は, 日本ミリポア製 Milli-Q SP TOC により 精製した，比抵抗 $18.0 \mathrm{M} \Omega \mathrm{cm}$ 以上のものを使用した. $\mathrm{HCl}(30 \%), \mathrm{NH}_{4} \mathrm{OH}(20 \%), \mathrm{H}_{2} \mathrm{O}_{2}(35 \%)$, 及び $\mathrm{HBr}$ (47\%) は，いずれも多摩化学製 Tamapure AA-100を 超純水で適宜希釈して使用した. マトリックス修飾剤と して使用した $2 \% \mathrm{NH}_{4} \mathrm{Cl}-10 \% \mathrm{HBr}$ 溶液は，上記の $\mathrm{HCl} 4.0, \mathrm{NH}_{4} \mathrm{OH} 6.8$, 及び $\mathrm{HBr} 21 \mathrm{ml}$ を混合し, 100 $\mathrm{ml}$ として調製した. $\mathrm{Si}$ 標準溶液は, 関東化学製原子吸 光分析用 $1 \mathrm{mg} \mathrm{ml}$-1 $^{-1}$ 溶を, 使用の都度 $8 \times 10^{-3} \mathrm{M}$ $\mathrm{NH}_{4} \mathrm{OH}-10 \times 10^{-3} \mathrm{M} \mathrm{H}_{2} \mathrm{O}_{2}$ 溶液で適宜希釈して使用し た. GFAAS の測定条件の検討及び添加検量線の作成に 使用した GaAs 溶液は，表面を十分に洗浄した Aldrich 製の $\mathrm{GaAs}$ 結晶 (99.999\%) を， $8 \times 10^{-3} \mathrm{M} \mathrm{NH}_{4} \mathrm{OH}^{-}$ $10 \times 10^{-3} \mathrm{M} \mathrm{H}_{2} \mathrm{O}_{2}$ 溶液に適宜溶解して調製した.

\section{2・3 定量操作}

今回の実験において, GFAAS 測定はクラス 1000 の クリーンルーム内で行い, 前処理操作はクリーンルーム 内に設置したクラス 100 のクリーンドラフト内で行っ た.

$\mathrm{GaAs}$ ウェハーの分析しようとする面にポリプロピレ ンリングを載せ, 溶解溶液 $\left(8 \times 10^{-3} \mathrm{M} \mathrm{NH}_{4} \mathrm{OH}^{-}\right.$ $10 \times 10^{-3} \mathrm{M} \mathrm{H}_{2} \mathrm{O}_{2}$ 溶液) $0.5 \mathrm{ml}$ をリング内側に滴下し た.この上に分析しようとする面を下にしたウェハーを 載せて， 2 枚のウェハーでポリプロピレンリング及び溶
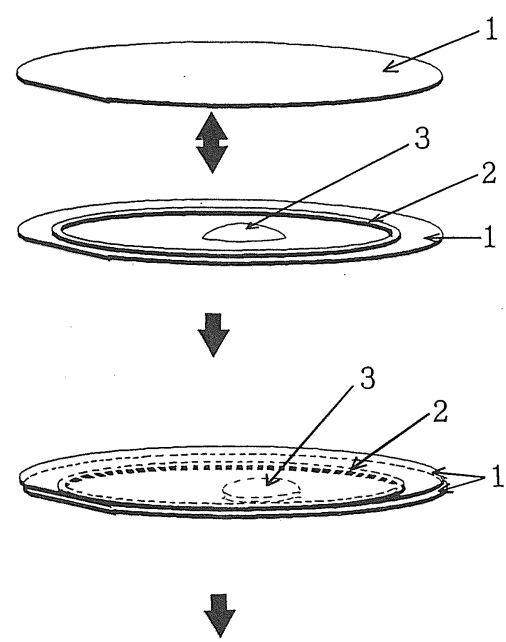

shake for 3 min

measurement of $\mathrm{Si}$ by GFAAS

Fig. 1 Schematic diagram of determination of $\mathrm{Si}$ on the surface of GaAs wafers by GFAAS

1: GaAs wafer; 2: polypropylene ring; $3: \mathrm{NH}_{4} \mathrm{OH}^{-}$ $\mathrm{H}_{2} \mathrm{O}_{2}$ solution

Table 1 Measurement conditions for GFAAS

\begin{tabular}{|c|c|c|c|c|}
\hline \multicolumn{2}{|c|}{ Wavelength } & \multicolumn{3}{|l|}{$251.6 \mathrm{~nm}$} \\
\hline \multicolumn{2}{|c|}{ Slit width } & \multicolumn{3}{|l|}{$0.20 \mathrm{~nm}$} \\
\hline \multicolumn{2}{|c|}{ Measurement type } & \multicolumn{3}{|c|}{ peak height } \\
\hline \multicolumn{2}{|c|}{ Background correction } & \multicolumn{3}{|l|}{ Zeeman } \\
\hline \multicolumn{2}{|c|}{ Sample volume } & \multicolumn{3}{|c|}{$\begin{array}{l}120 \mu \mathrm{l} \\
(40 \mu \mathrm{l} \times 3 \text { times injection })\end{array}$} \\
\hline \multicolumn{2}{|l|}{ Modifier } & \multicolumn{3}{|c|}{$40 \mu \mathrm{l}\left(2 \% \mathrm{NH}_{4} \mathrm{Cl}+10 \% \mathrm{HBr}\right)$} \\
\hline \multicolumn{5}{|c|}{ Heat program } \\
\hline Step & & temp $/{ }^{\circ} \mathrm{C}$ & $\mathrm{ramp} / \mathrm{s}$ & hold/s \\
\hline 1 & Drying & 110 & 20 & 10 \\
\hline 2 & Pre-ashing & 130 & 20 & 30 \\
\hline 3 & & 200 & 70 & 10 \\
\hline 4 & & 250 & 90 & 10 \\
\hline 5 & & 300 & 90 & 10 \\
\hline 6 & & 340 & 40 & 50 \\
\hline 7 & Ashing & 1000 & 20 & 10 \\
\hline 8 & Atomizing & 2500 & & 5 \\
\hline 9 & Gleaning & 2600 & 1 & 5 \\
\hline 10 & & 20 & 1 & 3 \\
\hline 11 & & 2600 & 1 & 5 \\
\hline
\end{tabular}

解溶液を挟み込むように保持した後, 溶液がこぼれない ように注意しながら 3 分間振り混ぜて $\mathrm{Si}$ を溶解させた (Fig. 1).この後得られた溶液中の Si GFAAS によ 
り測定した．GFAAS の条件を Table 1 に示す．測定に おいては, 1 回につき $40 \mu \mathrm{l}$ の試料溶液を, 乾燥段階で 3 回炉内濃縮を行った後, $40 \mu \mathrm{l}$ のマトリックス修飾剤 （2\% $\mathrm{NH}_{4} \mathrm{Cl}-10 \% \mathrm{HBr}$ 溶液）を添加することとした.

\section{3 結果及び考察}

\section{$3 \cdot 1$ 溶解溶液の検討}

$\mathrm{GaAs}$ ウェハー表面の $\mathrm{Si}$ を溶解させるためには, GaAs ウェハーの極表面を溶解することが必要である. $\mathrm{GaAs}$ を溶解できる液の組成として, $\mathrm{HCl}-\mathrm{Br}_{2}$ 溶液 ${ }^{133)}$, $\mathrm{HCl}-\mathrm{HNO}_{3}$ 溶液 (王水), $\mathrm{H}_{2} \mathrm{SO}_{4}-\mathrm{H}_{2} \mathrm{O}_{2}$ 溶液, $\mathrm{NH}_{4} \mathrm{OH}^{-}$ $\mathrm{H}_{2} \mathrm{O}_{2}$ 溶液等が考えられる。しかし, $\mathrm{HCl}-\mathrm{Br}_{2}$ 溶液は反 応が激しく, 今回目的とした極表面の溶解には不適当で あった. 又, 王水及び $\mathrm{H}_{2} \mathrm{SO}_{4}-\mathrm{H}_{2} \mathrm{O}_{2}$ 溶液では GFAAS 測定において, 今回目的とする $\mathrm{ng} \mathrm{ml}^{-1}$ 域の極微量の $\mathrm{Si}$ の定量を行うための十分な感度が得られなかった。 以上のことから, 溶解反応が比較的穏やかであり, かつ GFAAS で $\mathrm{ng} \mathrm{ml}^{-1}$ 域の $\mathrm{Si}$ の測定が可能であった $\mathrm{NH}_{4} \mathrm{OH}-\mathrm{H}_{2} \mathrm{O}_{2}$ 溶液を用いることとした.

\section{3 -2 溶解方法, 溶解溶液量, 及び溶解溶液濃度の検 討}

GaAs ウェハーは通常, 表面部に数 $\mathrm{nm}$ 程度の自然酸 化膜を有し親水性であるため, 溶解溶液は滴下した部分 にとゼまり，ウェハー上を移動させることができなかっ た. ウェハー表面のできるだけ多くの部分を溶解させる ためには，溶解溶液量を多くする方法が考えられるが, $\mathrm{Si}$ が希釈されるため感度が低下するという問題がある. そこで，Fig. 1 に示した方法を考案した．この方法で は, $1 \mathrm{ml}$ 以下の少量の溶解溶液を, 2 枚のウェハー及 びポリプロピレンリングによって保持するため, 振り混 ぜてもこぼれることなくリング内側表面を溶解させるこ とが可能であった. 又, 溶解面積を大きくできるので, 高感度化が可能であると考えられる。

そこで Fig. 1 に示した方法により, 溶解溶液量, 及 び溶解溶液中の $\mathrm{NH}_{4} \mathrm{OH}-\mathrm{H}_{2} \mathrm{O}_{2}$ 濃度について検討した. 溶解溶液量を $0.3,0.5$, 及び $1.0 \mathrm{ml}$ として溶解の操作 性について検討したところ, $1.0 \mathrm{ml}$ ではウェハーを振り 混ぜる際に溶液がこぼれることがあり，0.3 $\mathrm{ml}$ では溶液 がポリプロピレンリングに付着してウェハー表面を均一 に溶解させることができなかった．よって，今回の実験 では最も操作性が良好であった $0.5 \mathrm{ml}$ を用いることと した.

次に 2 インチウェハーを用いて, $0.5 \mathrm{ml}$ 溶解溶液中 の $\mathrm{NH}_{4} \mathrm{OH}-\mathrm{H}_{2} \mathrm{O}_{2}$ 濃度を $8 \times 10^{-3} \sim 10 \times 10^{-3}, 12 \times$
$10^{-3} \sim 15 \times 10^{-3}, 24 \times 10^{-3} \sim 30 \times 10^{-3} \mathrm{M}$ と変化させ て溶解操作を行い, 得られた溶液中の $\mathrm{Ga}$ 及び As を誘 導結合プラズマ発光分析法 (IGP-AES) で測定, GaAs 溶解量を求めた。その結果, 得られた溶解量はそれぞれ 240，410，1280 $\mu \mathrm{g}$ であった，なお，同一濃度の溶解溶 液を用いた場合の $\mathrm{GaAs}$ 溶解量は 2 及び 3 インチウェ 八ーでほぼ同様の值であった．ウェハー表面の $\mathrm{Si}$ を定 量する点を考慮すると, GaAs の溶解量が少ないとウェ 八一表面の $\mathrm{Si}$ を十分に溶解できない可能性がある。一 方溶解量が多過ぎるとウェハー中に含まれる $\mathrm{Si}$ の影響 が大きくなる可能性がある，又，後述する GFAAS に よる測定において，共存する $\mathrm{Ga}$ 及び As の影響が大き くなることも考えられる.よって, $8 \times 10^{-3} \mathrm{M} \mathrm{NH}_{4} \mathrm{OH}^{-}$ $10 \times 10^{-3} \mathrm{M} \mathrm{H}_{2} \mathrm{O}_{2}$ 溶液を用いることとした。この条件 において溶解される GaAs ウェハーの溶解深さは，2 枚 のウェハーの合計として，2 インチウェハーで約 40 $\mathrm{nm}, 3$ インチウェハーで約 $14 \mathrm{~nm}$ であった．次にこの 2 枚のウェハーのそれぞれの溶解深さをレーザー干渉表 面粗さ計によって測定したところ，溶解深さは 2 及び 3 インチのそれぞれについて，2 枚のウェハーでほぼ同一 の值であった，又，溶解操作を繰り返し行い，溶解深さ の再現性を確認したところ，相対標準偏差（RSD）とし て 2 インチウェハーで $3.7 \%$, 3 インチウェハーで $4.7 \%$ であった。 よって, 今回決定した条件で, $\mathrm{GaAs}$ の溶解が効果的に行えることが磼認できた。

\section{$3 \bullet 3$ GFAAS による $\mathrm{Si}$ の測定における $\mathrm{Ga}$ 及び As の影響の低減}

GaAs ウェハーの溶解により得られた溶液中には，微 量の $\mathrm{Si}$ が $\mathrm{ng} \mathrm{ml}^{-1}$ 程度, 及びマトリックス成分として $\mathrm{Ga}$ 及び As が $500 \sim 600 \mu \mathrm{g} \mathrm{ml}^{-1}$ 程度含まれる.この溶 液を GFAAS により測定したところ，Ga 及び Asによ るものと思われるバックグラウンド吸収が見られ， $\mathrm{Si}$ 測定の再現性を著しく低下させた $\{$ Fig. 2(A) \}.そこ で，このバックグラウンドを低減させる方法について検 討した。中村ら ${ }^{1)}$ は，タングステンアトマイザーを用い た原子吸光法によって GaAs 結晶中の不純物を測定す る際, 試料を $\mathrm{HCl}$ 及び $\mathrm{Br}_{2}$ で溶解した後 $\mathrm{NH}_{4} \mathrm{Cl}$ を添 加して， $\mathrm{Ga}$ 及び $\mathrm{As}$ をアトマイザーにおいて揮散させ る方法を検討し，良好な結果を得ている，又，文献年に よれば， $\mathrm{Ga}$ 及び As の塩化物あるいは臭化物は低沸点 であり，200 $400^{\circ} \mathrm{C}$ で揮散できると考えられる．以上 のことから，この方法が今回の実験においても有効であ ると考え， $\mathrm{Ga}$ 及び As を塩化物あるいは臭化物として， 黒鉛炉内で揮散させることを検討した。 

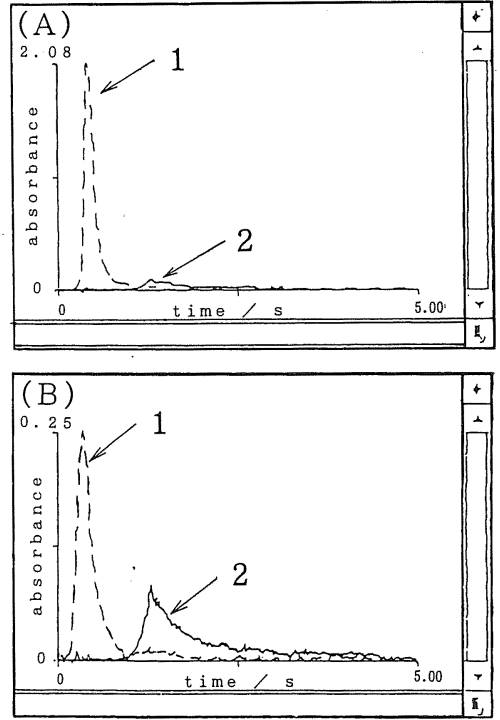

Fig. 2 Effects of additions of matrix modifier on measurement of $\mathrm{Si}$ in $\mathrm{Ga}$ and As solution by GFAAS (A): without matrix modifier; (B): with matrix modifier $\left(2 \% \mathrm{NH}_{4} \mathrm{Cl}-10 \% \mathrm{HBr}\right.$ solution, $\left.40 \mu \mathrm{l}\right) ; 1$ : background spectrum; 2 : Si spectrum

マトリックス修飾剤として $\mathrm{HCl}, \mathrm{HBr}, \mathrm{Br}_{2}$ 水, 及び $\mathrm{NH}_{4} \mathrm{Gl}$ を用い, これらの試薬の組み合わせを種々変え て $600 \mu \mathrm{g} \mathrm{ml}^{-1}$ の $\mathrm{Ga}$ 及び As を含む $10 \mathrm{ng} \mathrm{ml}^{-1} \mathrm{Si}$ 測 定におけるバックグラウンド吸光度の変化を観察したと ころ (Table 2)，10\% $\mathrm{HBr}$ 及び $5 \% \mathrm{NH}_{4} \mathrm{Cl}$ を用いた とき，バックグラウンド吸光度を大きく低減することが できた。この原因については更に詳しく検討を行う必要 があるが， $\mathrm{Ga}$ 及び As（いずれも酸素と結合した状態 で溶解していると考えられる）が $\mathrm{HBr}$ 及び $\mathrm{NH}_{4} \mathrm{Cl}$ と 反応し，臭化物あるいは塩化物となって揮散したためで はないかと考えられる．この $\mathrm{Ga}$ 及び As が揮散すると 考えられる温度, すなわち $200 \sim 400^{\circ} \mathrm{C}$ の予備洃化段階 において GFAAS の昇温速度が速いと Si の再現性が著 しく低下した. Ga 及び As の揮散とともに Si が揮散し ていることが原因であると考えられるので, Table 1 に 示したように，昇温に時間をかけることが必要であっ た.

次に $\mathrm{HBr}$ 及び $\mathrm{NH}_{4} \mathrm{Cl}$ 濃度を種々変えてバックグラ ウンド吸光度の変化を追跡するとともに, $10 \mathrm{ng} \mathrm{ml}^{-1} \mathrm{Si}$ 標準溶液を 3 回繰り返し測定し, RSDを求めた (Table 3). $\mathrm{NH}_{4} \mathrm{Cl}$ 及び $\mathrm{HBr}$ 量を増やすとバックグラ ウンド吸光度は小さくなったが, Si の繰り返し測定の
Table 2 Effects of additions of $\mathrm{HCl}, \mathrm{HBr}, \mathrm{Br}_{2}$, and $\mathrm{NH}_{4} \mathrm{Cl}$ as a matrix modifier on background spectra by GFAAS

\begin{tabular}{ccccc}
\hline \multicolumn{3}{c}{ Matrix modifier solution $^{\mathrm{a})}$} & $\begin{array}{c}\text { Absorbance of } \\
\text { background } \\
\text { b\% }\end{array}$ \\
\hline (peak height)
\end{tabular}

$\bigcirc$ : added; - : not added.

a) $20 \mu \mathrm{l}$ of the matrix modifier solution was added. b) $120 \mu \mathrm{l}$ of the sample solution $\left(10 \mathrm{ng} \mathrm{ml}^{-1} \mathrm{Si}\right.$ and $600 \mu \mathrm{g} \mathrm{ml}^{-1} \mathrm{Ga}$ and As in $8 \times 10^{-3} \mathrm{M} \mathrm{NH} 4 \mathrm{OH}$ $10 \times 10^{-3} \mathrm{M} \mathrm{H}_{2} \mathrm{O}_{2}$ ) was used as a test solution.

Table 3 Effects of $\mathrm{NH}_{4} \mathrm{Cl}$ and $\mathrm{HBr}$ concentrations on background spectra and on reproducibilities of Si by GFAAS.

\begin{tabular}{|c|c|c|c|}
\hline \multicolumn{2}{|c|}{ Concentration $^{\text {a) }}$} & \multirow{2}{*}{$\begin{array}{l}\text { Absorbance of } \\
\text { background } \\
\text { (peak height) }\end{array}$} & \multirow{2}{*}{$\underset{\%}{\mathrm{RSD}} \underset{\%}{\mathrm{Si}} \mathrm{i}^{\mathrm{b})}$} \\
\hline$\underset{\%}{\mathrm{NH}_{4} \mathrm{Cl}}$ & $\underset{\%}{\mathrm{HBr}}$ & & \\
\hline 2 & 10 & 0.22 & 0.9 \\
\hline 5 & 10 & 0.10 & 2.1 \\
\hline 8 & 10 & 0.09 & 3.5 \\
\hline 10 & 10 & 0.11 & 4.0 \\
\hline 8 & 2.5 & 0.42 & 1.1 \\
\hline 8 & 5.0 & 0.28 & 2.2 \\
\hline 8 & 7.5 & 0.16 & 3.9 \\
\hline 8 & 20 & 0.08 & 5.7 \\
\hline
\end{tabular}

a) $40 \mu \mathrm{l}$ of the matrix modifier solution was used.

b) Estimated by 3 repetitive measurements of the sample solution $\left(120 \mu \mathrm{l}\right.$ of $10 \mathrm{ng} \mathrm{ml}^{-1} \mathrm{Si}$ and $600 \mu \mathrm{g}$ $\mathrm{ml}^{-1} \mathrm{Ga}$ and $\mathrm{As}$ in $8 \times 10^{-3} \mathrm{M} \mathrm{NH}_{4} \mathrm{OH}^{-10} \times 10^{-3}$ $\mathrm{M} \mathrm{H}_{2} \mathrm{O}_{2}$ ).

RSD が大きくなる傾向にあった. そこで，バックグラ ウンド吸光度が比較的小さく, Si の繰り返し測定の RSD が最も小さい，2\% $\mathrm{NH}_{4} \mathrm{Cl}-10 \% \mathrm{HBr}$ 溶液 $(40 \mu \mathrm{l})$ を用いることとした．このマトリックス修飾剤を添加し て測定した結果，Fig. 2(B) に示したように，バックグ ラウンド吸光度を約 $1 / 10$ とすることができた. 又, Table 3 に示したように, Si のシグナルを安定化させる ことができた. 


\section{$3 \cdot 4$ 検量線}

$\mathrm{Si}$ 濃度を段階的に変化させた $8 \times 10^{-3} \mathrm{M} \mathrm{NH}_{4} \mathrm{OH}^{-}$ $10 \times 10^{-3} \mathrm{M} \mathrm{H}_{2} \mathrm{O}_{2}$ 溶液（標準溶液）を用いて検量線を 作成した. 又, $600 \mu \mathrm{g} \mathrm{ml}^{-1} \mathrm{GaAs}$ 溶液に同様に $\mathrm{Si}$ 標準 溶液を段階的に添加して添加検量線を作成し, 比較を行 った。 その結果, 両者の検量線の直線性は良好であり， 傾き及び空試験值もほぼ一致した。よって，定量の際に 用いる検量線には $\mathrm{GaAs}$ を共存させる必要がないこと が分かった. 定量下限は空試験の繰り返し測定 $(n=5)$ の標準偏差の 10 倍に相当する濃度として, $2 \mathrm{ng} \mathrm{ml}^{-1}$ であった。このときの標準溶液による検量線の相関係数 は 0.9995 , 空試験の $\mathrm{Si}$ 相当濃度は $3.5 \mathrm{ng} \mathrm{m}^{-1}, 5$ 回繰 り返し測定における $\mathrm{RSD}$ は Si $5 \mathrm{ng} \mathrm{ml}^{-1}$ で $5.9 \%$ ， $20 \mathrm{ng} \mathrm{ml}^{-1}$ で $2.6 \%$ であった.

\section{3 •5 GaAs ウェハー表面の $\mathrm{Si}$ の定量}

本法により市販の数種類の GaAs ウェハー(ノン ドープ品) のミラー面について定量を行った．定量操作 においては，2 枚のウェハーの同一個所についてそれぞ れ 3 回ずつ繰り返し溶解操作を行い, それぞれ GFAAS によって測定した. Table 4 に示した結果では，Si 濃度 は $10^{11} \sim 10^{13}$ atoms $\mathrm{cm}^{-2}$ の範囲であることが分かっ た。試料 $\mathrm{A}, \mathrm{C}$, 及び $\mathrm{E}$ では 1 回目の溶解操作におい てのみ $\mathrm{Si}$ が検出されたが, 2 回目以降は GFAAS の定 量下限以下の值であった。このことから, Si は 1 回の 溶解操作で十分に溶解されていることが確認できた.

又, 前処理中の環境からの $\mathrm{Si}$ の污染は無視できる程度

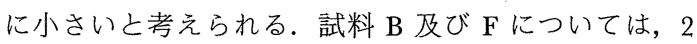
回目の溶解操作においても $\mathrm{Si}$ が定量された. 通常ノン ドープウェハーでは, 固体中に含まれる $\mathrm{Si}$ 量は $10^{14-}$ $10^{16}$ atoms $\mathrm{cm}^{-3}$ 程度であるため, GaAs ウェハーの表 面〜数十 $\mathrm{nm}$ 程度の溶解において, 固体中に含まれる $\mathrm{Si}$ が $10^{12}$ atoms $\mathrm{cm}^{-2}$ 程度の定量值に対して影響を与 えることは考えにくい. よって, 試料 B 及び F のウェ ハーは, 表面近傍に Si が多く含まれる試料であったた
Table 4 Analytical results of $\mathrm{Si}$ on GaAs wafers (Unit: $10^{11}$ atoms $\mathrm{cm}^{-2}$ )

\begin{tabular}{|c|c|c|c|c|}
\hline \multirow[b]{2}{*}{ Wafer } & \multirow[b]{2}{*}{ Sample } & \multicolumn{3}{|c|}{ Analytical results ${ }^{\dagger}$} \\
\hline & & $\begin{array}{l}\text { First } \\
\text { time }\end{array}$ & $\begin{array}{c}\text { Second } \\
\text { time }\end{array}$ & $\begin{array}{l}\text { Third } \\
\text { time }\end{array}$ \\
\hline \multicolumn{5}{|l|}{ 2-inch } \\
\hline \multirow{6}{*}{ 3-inch } & A & 47 & $<14$ & $<14$ \\
\hline & B & 310 & 22 & $<14$ \\
\hline & G & 29 & $<14$ & $<14$ \\
\hline & $\mathrm{D}$ & $<4$ & $<4$ & $<4$ \\
\hline & $\mathrm{E}$ & 5 & $<4$ & $<4$ \\
\hline & $\mathrm{F}$ & 50 & 11 & $<4$ \\
\hline
\end{tabular}

$\dagger$ The determination procedure was repeated three times for the same place of the GaAs wafers.

め, 1 回目の溶解操作で $\mathrm{Si}$ を十分に溶解できなかった か, あるいは溶解操作において振り混ぜが不十分であっ たため, 1 回目の溶解操作では十分に溶解できなかった ことが考えられる. 3 回目の溶解操作における定量值は GFAAS の定量下限以下であった。 よって, 試料 B 及 び F のウェハー表面の $\mathrm{Si}$ 濃度は, 1 回目の定量值及び 2 回目の定量値の和であると考えられる.

以上の結果から本法では, $10^{11}$ atoms $\mathrm{cm}^{-2}$ レベルの $\mathrm{Si}$ が定量でき, GaAs ウェハーの微量不純物である $\mathrm{Si}$ の定量として有効な分析法であると評価できる.

本研究を行うに当たり，ご指導，ご助言をいただきまし た名古屋大学工学部原口紘喣教授に厚く御礼申し上げます。 (1996 年 9 月, 日本分析化学会) 第 45 年会において一部発表

\section{文献}

1) 中村 靖, 小林義男: 分析化学 (Bunseki Kagaku), 35, 446 (1986).

2）小塚祥二, 林 勝, 松永英樹: 日本分析化学会 第 43 年会講演要旨集, p.610(1994).

3) W. Maenhaut: Anal. Chem. Acta, 75, 31(1975).

4) 日本化学会編: 改訂 4 版 “化学便覧”, (1993), (丸善)。 


\section{要旨}

ヒ化ガリウムウェハー表面（表面～数十 $\mathrm{nm}$ 付近）に存在するケイ素を黒鉛炉原子吸光法により定 量するための検討を行い, 以下の結果を得た。（1）ウェハーの溶解には, アンモニア-過酸化水素溶液 が適当であった，溶解操作では 2 枚のウェハーの分析しようとする面で，ポリプロピレン製リング及 び溶解溶液を挟み, 振り混ぜることによりウェハーを溶解してケイ素を溶解させるとともに, 溶解面積 を大きくすることにより検出感度を高めることができた. (2) 黒鉛炉原子吸光法による測定では, 塩化 アンモニウムー臭化水素酸溶液をマトリックス修飾剤とし, 共存ガリウム及びヒ素を低温で揮散させる ことにより，ケイ素のシグナルのばらつきを低減した．定量下限は，空試験溶液の繰り返し測定におけ る標準偏差の 10 倍に相当する濃度として, $2 \mathrm{ng} \mathrm{ml}^{-1}$ であった.この值は 2 インチウェハーで $14 \times 10^{11}, 3$ インチウェハーで $4 \times 10^{11}$ atoms $\mathrm{cm}^{-2}$ に相当する. 